\title{
Gaya Belajar, Motivasi Berprestasi, Locus of Control dan Academic Self- Concept Mahasiswa FIK Uncen
}

\author{
Mifta Fariz Putra \\ Jurusan Pendidikan Jasmani Kesehatan dan Rekreasi, FIK Universitas Cenderawasih, Jayapura
}

${ }^{*}$ Corresponding author: putra.uncen@gmail.com

\begin{tabular}{l} 
A R T I C L E I N F O \\
\hline Article history: \\
Received 01 August 16 \\
Received in revised form 18 August 16 \\
Accepted 13 September 16 \\
\hline Keywords: \\
Learning style; Achievement \\
motivation; Locus of control; Academic \\
self concept
\end{tabular}

\section{A R T ICLE INFO}

Article history:

Received 01 August 16

Received in revised form 18 August 16

Accepted 13 September 16

Keywords:

motivation; Locus of control; Academic

self concept

\begin{abstract}
A B S T R A C T
The aim of this research was to find out (1) profile of learning style, achievement motivation, locus of control, academic self-concept of the college student of FIK Uncen, (2) difference of learning style, achievement motivation, locus of control, academic self-concept of the college student of FIK Uncen to view gender. The result of this research was (1) there was $7(9,6 \%)$ college students that have visual learning style, $19(26,0 \%)$ college students that have aural learning style, $16(21,9 \%)$ college students that have read/write learning style, $31(42,5 \%)$ college students that have kinesthetic learning style. There was no difference learning style to view gender, (2) the mean of achievement motivation of the effort dimension have more higly score (29) than both the choice dimension (21) and the persistence dimension (19). There was no difference achievement motivation to view gender, (3) there was $63(86,3 \%)$ college students that have internal locus of control and $10(13,7 \%)$ college students have external locus of control. There was no difference locus of control to view gender (4) there was $18(24,7 \%)$ college students that have high academic self-concept, $55(75,3 \%)$ college students that have medium academic self-concept, and $0(0 \%)$ college students that have low academic self-concept. There was no difference academic self-concept to view gender.
\end{abstract}

\section{Pendahuluan}

Menyoal tentang pembelajaran maka variabel yang melingkupinya tidaklah beralur tunggal namun multi variabel. Oleh Reigeluth (1983) variabel pembelajaran dibagi menjadi tiga variabel besar, yaitu: hasil, metode dan kondisi. Dalam taxonominya tampak bahwa hasil pembelajaran akan dipengaruhi oleh variabel metode pembelajaran, kemudian variabel metode pembelajaran akan bergantung pada bagaimana kondisi mahasiswa, seperti karaktertstik kepribadian mahasiswa (gaya belajar, motivasi berprestasi, locus of control, academic self-concept dan variabel psikologis lainnya). Artinya, pendidik (dosen) perlu mengetahui dan mempertimbangkan variabel karakteristik kepribadian mahasiswa dalam merancang pembelajarannya, sehingga academic excellence (keunggulan akademik) akan terwujud dalam proses belajar mengajar di kampus.

Pertanyaan yang relevan untuk diajukan dalam konteks ini adalah apakah terdapat bukti teoretik dan empirik bahwa variabel karaktertstik kepribadian di atas berhubungan dan/atau berpengaruh terhadap pembelajaran? Untuk menjawab pertanyaan tersebut penulis akan mencuplik beberapa pendapat ahli dan temuan penelitian di lapangan.

Lain sungai lain ikannya, lain orang maka lain pula gaya belajarnya. Perumpaan di atas penulis yakini sesuai dalam konteks pembelajaran karena memang terdapat sebagian yang lebih suka belajar dengan cara mendengarkan, sebagian lagi belajar dengan cara mengamati, sebagian lainnya lebih suka belajar dengan cara membaca, dan sebagian lagi lebih suka belajar dengan cara mempraktikan langsung gerakan. Cara belajar mahasiswa yang beragam tersebut disebut oleh pakar sebagai gaya belajar atau learning style (Philibin, et.al., 1995).

Kendati telah muncul hampir empat dekade, istilah gaya belajar belum memiliki pengertian baku (Tjundjing, 2003). Oleh James dan Blank (1993) gaya belajar didefinisikan sebagai kebiasaan belajar seseorang di mana ia merasa paling efisien dan efektif dalam menerima, memproses, menyimpan dan mengeluarkan sesuatu yang dipelajarinya. Pakar lain, McLoughlin (1999) menyatakan bahwa istilah gaya belajar merujuk pada kebiasaan dalam memperoleh pengetahuan. Dalam tulisan ini gaya belajar dimaknai sebagai cara belajar yang paling disukai seseorang dalam memahami sesuatu yang dipelajarinya..

Fleming dan Mills (1992) membagi gaya belajar menjadi empat, yaitu: Pertama, Visual (V). Mahasiswa yang memiliki gaya belajar visual (visual learners) akan cenderung lebih suka belajar dengan memanfaatkan ketajaman penglihatannya. Mereka akan lebih mudah memahami dengan cara melihat secara visual informasi-informasi dalam bentuk gambar, peta, grafik, dan simbol. Kedua, Aural (A). Mahasiswa yang memiliki gaya belajar aural (aural learners) akan cenderung lebih suka belajar dengan memanfaatkan pendengarannya. Pelajar dengan gaya belajar ini akan lebih mudah memahami informasi yang dipelajarinya dengan mengikuti tutorial, perkuliahan ceramah, kaset rekaman, dan berdiskusi dengan teman. Ketiga, Read/write (R). Mahasiswa yang memiliki gaya belajar read/write (read/write learners) akan cenderung lebih suka belajar dengan cara membaca tulisan. Mereka akan lebih mudah memahami informasi dengan cara membaca tulisan yang ada di buku, artikel, dan sumber lain yang sejenis. Keempat, Kinesthetic (K). 
Mahasiswa yang memiliki gaya belajar kinesthetic (kinesthetic learners) akan cenderung lebih suka belajar dengan cara mendapatkan contoh pengalaman secara langsung dan praktik karena mereka akan lebih mudah memahami apa yang dipelajarinya apabila diberi kesempatan untuk mempraktikkannya secara langsung.

Variabel kedua yang dikaji dalam studi ini adalah motivasi berprestasi. Membahas motivasi berprestasi maka tidak dapat dilepaskan dari sosok David McClelland. Dalam bukunya yang fenomenal yaitu "The Achieving Society", McClelland (1961) menyatakan bahwa motivasi manusia terdiri dari tiga kebutuhan yang dominan, seperti: kebutuhan berprestasi (need for achievement), kebutuhan kekuasaan (need for power), dan kebutuhan afiliasi (need for affiliation). Setiap kebutuhan individu akan bervariasi dan bergantung pada latar belakang budaya masing-masing. Lebih lanjut ia menyatakan bahwa intensitas jenis kebutuhan tersebut akan berpengaruh besar terhadap perubahan sosial dan evolusi masyarakat.

Secara sederhana motivasi berprestasi dapat dipahami sebagai motivasi yang tujuannya adalah meraih prestasi (Purwanto, 2011). Oleh Nicholl (1984) motivasi berprestasi dimaknai sebagai motivasi yang ditujukan untuk mengembangkan ataupun mendemonstrasikan kemampuan yang tinggi. Orang yang disebut berprestasi adalah mereka yang berhasil mengembangkan atau mendemonstrasikan kemampuan yang dimilikinya dengan optimal. Singkatnya, motivasi berprestasi adalah motivasi yang bertujuan untuk mengejar prestasi.

Sebagai suatu proses maka motivasi berprestasi tidak dapat diobservasi secara langsung, namun hanya dapat disimpulkan melalui tingkahlaku. Schunk, Pintrich \& Meece (2008) serta Wigfield \& Eocles (2002) mengemukakan bahwa indikator dari motivasi berprestasi, khususnya dalam bidang akademik meliputi tiga hal, yaitu: pilihan (choice), keuletan (persistance), dan usaha (effort). Secara singkat ketiga indikator di atas dapat dijelaskan sebagai berikut.

Pilihan (choice) adalah kecenderungan untuk melibatkan diri secara aktif dalam tugas akademik ketimbang tugas non-akademik, di mana pada saat yang sama ia memiliki kesempatan untuk melakukan aktivitas lain yang juga menarik untuk dilakukan. Perilaku memilih tugas akademik ini, misalnya, memilih mengerjakan tugas perkuliahan ketimbang menenton TV, menelepon teman, bermain game dan aktivitas bermain lainnya. Keuletan (persistance) adalah kesediaan individu untuk terus berusaha menyelesaikan suatu tugas, terutama pada waktu menghadapi rintangan seperti kesulitan, kebosanan, ataupun kelelahan. Individu yang dikatakan persistennya tinggi pada suatu tugas adalah mereka yang tampak dari keuletannya untuk terus mengerjakan tugas tersebut sampai selesai. Sebaliknya individu yang persistensinya rendah adalah mereka yang ketika menghadapi tugas sulit akan mengalami kebosanan, mudah menyerah, dan beralih melakukan aktivitas yang lain. Usaha (effort) adalah kesediaan untuk mengerahkan usaha baik berupa usaha secara fisik maupun usaha secara kognitif. Perilaku yang mencerminkan usaha ini misalnya berupa mengajukan pertanyaan yang bagus ketika di kelas, mendiskusikan materi pelajaran dengan teman sekelas atau teman lain di luar jam sekolah, memikirkan secara mendalam materi pelajaran yang sedang dipelajari, menggunakan waktu secara memadai untuk mempersiapkan ujian, merencanakan aktivitas belajar dan sebagainya.

Oleh Schunk, Pintrich \& Meece (2008) indikator tersebut ditambah dengan prestasi (achievement) yang mereka sebut sebagai indikator tidak langsung. Oleh Purwanto (2011) indikator ini tidak dimasukkan dalam indikator motivasi berprestasi mengingat prestasi adalah hasil dari banyak variabel. Penulis sependapat dengan Purwanto (2011) karena memasukkan indikator prestasi dalam indikator motivasi berprestasti dipandang kurang logis.

Variabel ketiga dalam riset ini adalah locus of control. Konsep locus of control pertama kali dikemukakan oleh Rotter (1966) yaitu seorang ahli teori pembelajaran sosial dari Amerika. Menurut Rotter locus of control merupakan salah satu variabel kepribadian (personality) yang berkaitan dengan keyakinan individu bahwa mereka mampu mengontrol peristiwa-peristiwa dalam kehidupannya atau sebaliknya bahwa lingkunganlah yang mampu mengontrol peristiwa-peristiwa dalam kehidupannya. Owie (1993) menyebutkan bahwa locus of control adalah karakteristik individu yang didasarkan pada keyakinan bahwa kehidupan seseorang ditentukan oleh kombinasi kekuatan internal dan eksternal. Oleh Murisal (2003) keyakinan itu disebutkan akan menjadi sumber penentu perilaku seseorang. Hal yang tidak jauh berbeda diungkapkan oleh Capel (1992) bahwa locus of control merupakan persepsi umum terhadap hubungan antara perilaku dengan peristiwa yang menyertainya. Menurut Degeng dan Pali (2002) lokus kendali merupakan kecenderungan pebelajar terhadap general expectancy (harapan umum) dalam menerima hadiah dan hukuman sebagai variabel yang berpengaruh dalam bertingkahlaku. Senada dengan itu, Abimanyu (1990) menyebutkan locus of control adalah cara pebelajar menyikapi reinforcement yang diterimannya. Putra (2012) yang mensintesiskan berbagai pengertian di atas sampai pada simpulan bahwa locus of control dapat dipahami sebagai kecenderungan seseorang dalam menyikapi apa yang diterimanya (reinforcement) apakah dipersepsikan sebagai faktor dari dalam (internal orientation) atau faktor dari luar (external orientation). Dengan demikian terdapat dua orientasi locus of control, yaitu orientasi internal dan eksternal. Secara singkat orietasi locus of control internal dan eksternal dapat dijelaskan sebagai berikut.

Rosen dan Osmon (dalam Degeng dan Pali, 2002) menyebutkan bahwa seseorang dikatakan memiliki orientasi lokus kendali internal bila ia menganggap reinforcement yang diterimanya sebagai konsekuensi logis dari hasil kerja keras dirinya sendiri. Senada dengan itu Abimanyu (1990) menyatakan bahwa jika pebelajar lebih menganggap reinforcement yang diterimanya sebagai konsekuensi logis dari hasil kerja dirinya sendiri, maka pebelajar demikian dikatakan memiliki lokus kendali internal. Mahasiswa yang memiliki lokus kendali internal memiliki kecenderungan sifat yang lebih aktif dalam mencari, mengelola, memanfaatkan berbagai informasi, serta memiliki motivasi berprestasi yang tinggi (Mukhadis, 2003; Degeng dan Pali, 2002).

Sementara itu mahasiswa yang memiliki keyakinan bahwa lingkunglah yang mempunyai kontrol terhadap nasib atau kejadian yang 
terjadi dalam kehidupannya, maka ia termasuk memiliki locus of control eksternal. Pebelajar yang memiliki orientasi locus of control eksternal menganggap keberhasilan yang dicapainya sebagai akibat kontrol dari keadaan sekitarnya. Ciri pebelajar yang orientasi locus of control-nya eksternal adalah ia lebih banyak menyandarkan harapannya untuk bergantung pada orang lain, dan lebih banyak mencari serta memilih situasi yang menguntungkan. Mahasiswa yang memiliki locus of control eksternal melihat keberhasilan dan kegagalan dari faktor kesukaran serta nasib. Oleh karena itu, apabila mengalami kegagalan, mereka cenderung menyalahkan lingkungan sekitar yang menjadi penyebabnya.

Zimbardo (1980) menyatakan locus of control merupakan dimensi kepribadian yang berupa kontinum dari eksternal menuju internal atau sebalinya. Oleh karenanya tidak satupun individu yang benar-benar internal atau yang benar-benar eksternal. Kedua tipe locus of control terdapat dalam setiap individu, hanya saja ada kecenderungan untuk lebih memiliki salah satu tipe locus of control tertentu. Di samping itu, locus of control tidak bersifat statis melainkan juga dapat berubah. Individu yang berorientasi locus of control internal dapat berubah menjadi individu yang berorientasi locus of control eksternal, dan juga sebaliknya. Hal tersebut disebabkan karena situasi dan kondisi yang menyertainya, yaitu di mana ia tinggal dan sering melakukan aktifitasnya.

Variabel keempat dalam studi ini adalah academic selfconcept. Sebelum membahas academic self-concept akan diuraikan singkat tentang self-concept terlebih dahulu. Oleh Hurlock (1999) selfconcept atau konsep diri diartikan sebagai gambaran diri tentang aspek fisiologis maupun psikologis yang berpengaruh pada perilaku individu dalam penyesuaian diri dengan orang lain. Agustiani (2006) menyatakan bahwa konsep diri juga merujuk pada gambaran tentang peran yang kita lakukan, yaitu yang terbentuk sebagai hasil dari makin banyak atau seringnya kita berinteraksi dengan orang lain.

Secara sederhana konsep diri dapat dipahami sebagai keyakinan, pandangan atau penilaian seseorang terhadap dirinya. Seseorang dikatakan mempunyai konsep diri negatif jika ia meyakini dan memandang bahwa dirinya lemah, tidak berdaya, tidak dapat berbuat apaapa, tidak kompeten, gagal, malang, tidak menarik, tidak disukai dan kehilangan daya tarik terhadap hidup. Sebaliknya orang dengan konsep diri yang positif akan terlihat lebih optimis, penuh percaya diri dan selalu bersikap positif terhadap segala sesuatu, bahkan terhadap kegagalan yang dialaminya sekalipun. Kegagalan bukan dipandang sebagai akhir segalanya, namun lebih menjadikannya sebagai penemuan dan pelajaran berharga untuk melangkah ke depan. Orang dengan konsep diri yang positif akan mampu menghargai dirinya dan melihat hal-hal positif yang dapat dilakukan demi keberhasilan di masa mendatang.

Pertanyaannya kemudian, apakah kaitannya konsep diri dengan academic self-concept? Gauy, Mars, \& Boivin (2003) menyatakan bahwa konsep diri dipandang oleh ilmuwan sebagai konstruk bertingkat yang terdiri dari beberapa komponen, salah satunya adalah academic selfconcept. Lent, Brown and Gore (1997) memberikan penjelasan yang mencerahkan tentang academic self-concept. Menurutnya "academic selfconcept refers to specific attitudes, feelings and perceptions about an individual's intellectual or academic abilities which represent that individual's self-beliefs and self-feelings regarding the academic setting”.

Mendasarkan pada uraian di atas maka dapat disimpulkan bahwa karakteristik kepribadian seperti gaya belajar, motivasi berprestasi, locus of control, dan academic self-concept merupakan variabel yang perlu diketahui dan dipertimbangkan pendidik (dosen) dalam merancang pembelajarannya. Oleh karena itu, kajian tentang gaya belajar, motivasi berprestasi, locus of control, dan academic self-concept dipandang menarik dan penting dilakukan agar kualitas belajar mengajar meningkat sehingga academic excellence dalam perkuliahan di Universitas Cenderawasih, khususnya di FIK Uncen dapat terwujud.

Secara khusus penelitian tersebut ditujukan untuk menjawab pertanyaan (1) Bagaimanakah profil gaya belajar, motivasi berprestasi, locus of control, dan academic self-concept mahasiswa FIK Uncen? (2) Apakah ada perbedaan gaya belajar, motivasi berprestasi, locus of control, dan academic self-concept mahasiswa FIK Uncen ditinjau dari jenis kelamin?

\section{Metode}

Studi ini dilakukan dengan tujuan untuk mengungkap profil gaya belajar, motivasi berprestasi, locus of control, dan academic selfconcept mahasiswa FIK Uncen serta untuk mengetahui ada tidaknya perbedaan variabel di atas ditinjau dari jenis kelamin mahasiswa FIK Uncen. Untuk mencapai tujuan itu, disusun rancangan penelitian sebagai berikut:

Studi ini akan menggunakan penelitian deskriptif. Ary, Jacobs, dan Razavieh (1990) menyebutkan "descriptive research is not generally directed toward hypotesis testing. The aim to describe "what exists" with respect to variables or conditions in situation (p.381). Populasi dalam penelitian ini adalah mahasiswa FIK Uncen. Sampel diambil dengan purposive random sampling. Dengan penggunaan teknik tersebut diharapka akan didapat subjek penelitian yang memiliki tingkat kemampuan tinggi, sedang, dan rendah. Artinya, subjek penelitian merupakan reprensentatif dari populasi yang sebenarnya, yaitu mencerminkan tingkatan kemampuan mahasiswa yang ada di FIK Uncen. Melalui teknik tersebut, peneliti mengambil sampel sebanyak 73 mahasiswa FIK Uncen.

Data penelitian akan dikumpulkan dengan menggunakan empat instrumen penelitian. Pertama, meskipun banyak instrumen untuk mengukur gaya belajar, studi ini akan menggunakan instrumen yang dikembangkan oleh Fleming dan Mills (1992). Pertimbangannya adalah karena intrumen Fleming dan Mills merupakan pengembangan dari instrumen gaya belajar sebelumnya yaitu VAK. Di samping itu, apa yang diungkapkan oleh Fleming dan Mills dipandang lebih relevan dan sesuai apabila menyebutnya sebagai gaya belajar. Dengan mengacu pada instrumen yang dikembangkan oleh Fleming dan Mills (1992) maka akan didapat empat jenis gaya belajar mahasiswa, yaitu: visual, aural, 
read/write, dan kinesthetic. Pada awalnya instrumen tersebut terdiri dari 13 item pernyataan, namun pada tahun 2006 oleh Fleming dan Baume direvisi sehingga item pernyataan berubah menjadi 16 .

Kedua, untuk mendapatkan data motivasi berprestasi mahasiswa, peneliti akan mengadaptasi skala motivasi berprestasi yang dikembangkan oleh Purwanto (2011). Mengingat instrumen tersebut dikembangkan dengan subjek coba siswa Sekolah Menengah Atas (SMA) maka akan ada beberapa redaksi pernyataan yang dirubah dan disesuaikan dengan konteks mahasiswa, khususnya mahasiswa Fakultas Ilmu Keolahragaan (FIK). Item pernyataan motivasi berprestasi berjumlah 20 item dengan empat alternatif jawaban, yaitu Sangat Tidak Sesuai (STS), Tidak Sesuai (TS), Sesuai (S), Sangat Sesuai (SS).

Ketiga, untuk mendapatkan data locus of control akan digunakan skala locus of control yang dikembangkan oleh Rotter (1966) dan telah digunakan oleh Putra (2012) dalam meneliti mahasiswa olahraga. Instrumen locus of control terdiri dari 29 pasang butir pernyataan, di mana tiap pasang butirnya terdiri dari pernyataan yang mengandung makna locus of control internal dan eksternal. Di antara 29 pernyataan itu, terdapat 6 butir pernyataan yang dipasang untuk mengaburkan subjek yang sedang menjawab. Tujuannya ialah agar jawaban mahasiswa benar-benar mencerminkan apa yang diyakininya dan bukan rekayasa jawaban. Oleh karena itu, keenam butir pernyataan tersebut tidak akan diskor.

Keempat, untuk mendapatkan data academic self-concept akan digunakan skala academic self-concept yang dikembangkan oleh Reynolds (1988). Intrumen tersebut terdiri dari 40 item pernyataan dengan empat alternatif jawaban, yaitu Sangat Tidak Setuju (STS), Tidak Setuju (TS), Setuju (S), Sangat Setuju (SS).

Semua instrumen yang digunakan dalam penelitian ini telebih dahulu akan dilakukan penyesuaian konteks, yaitu disesuaikan dengan situasi serta kondisi yang acapkali dihadapi dan ditemui oleh mahasiswa FIK. Penyesuaian konteks dilakukan dengan cara merevisi item-item pernyataan yang substansinya kurang atau tidak sesuai dengan subjek penelitian.

Data yang diperoleh akan dianalias secara deskriptif dengan menggunakan mean dan persentase. Untuk mengetahui perbedaan antara gaya belajar, motivasi berprestasi, locus of control, dan academic selfconcept yang ditinjau dari jenis kelamin maka akan digunakan analisis chi-square. Kenapa? Karena jenis data penelitian tersebut berbentuk nominal (kategorik). Hal ini sesuai dengan yang dijelaskan oleh Sugiyono (2010) dan Maksum (2012) bahwa jenis data nominal dapat dianalisis dengan chi square. Khusus untuk data motivasi berprestasi akan dianalisis dengan uji t independent karena jenis datanya interval. Semua analisis data akan dilakukan dengan bantuan program komputer, yaitu menggunakan SPSS V.21.

\section{Hasil dan Pembahasan}

Paparan data penelitian yang pertama akan mendeskripsikan tentang proporsi jenis kelamin kemudian akan diikuti uraian tentang profil dan perbandingan gaya belajar, motivasi berprestasi, locus of control, serta academic self-concept ditinjau dari jenis kelamin mahasiswa.

\section{Proporsi Jenis Kelamin Mahasiswa}

Berikut ini adalah deskripsi data jenis kelamin mahasiswa FIK Uncen:

Tabel 1. Proporsi Jenis Kelamin Mahasiswa

\begin{tabular}{ccc}
\hline Jenis Kelamin & Frekuensi & Persentase \\
\hline Laki-laki & 49 & $67,1 \%$ \\
Perempuan & 27 & $32,9 \%$ \\
\hline Total & 73 & $100 \%$ \\
\hline
\end{tabular}

Dari tabel $1 \mathrm{di}$ atas terlihat bahwa jumlah subjek penelitian laki-laki sebanyak $49(67,1 \%)$ mahasiswa, sedangkan mahasiswa perempuan sebanyak $27(32,9 \%)$ orang. Total mahasiswa yang menjadi subjek penelitian adalah 73 mahasiswa.

\section{Profil Gaya Belajar Mahasiswa}

Berikut ini adalah deskripsi data jenis kelamin mahasiswa FIK Uncen:

Tabel 2. Gaya Belajar Mahasiswa

\begin{tabular}{ccc}
\hline Gaya Belajar & Frekuensi & Persentase \\
\hline Visual & 7 & $9,6 \%$ \\
Aural & 19 & $26,0 \%$ \\
Read/write & 16 & $21,9 \%$ \\
Kinesthetic & 31 & $42,5 \%$ \\
\hline Total & 73 & $100 \%$ \\
\hline
\end{tabular}

Dari tabel 2 di atas tampak bahwa mahasiswa yang memiliki gaya belajar visual sebanyak $7(9,6 \%)$, gaya belajar aural sebanyak 19 (26,0\%), gaya belajar read/write sebanyak $16(21,9 \%)$ dan gaya belajar kinesthetic sebanyak $31(42,5 \%)$. Apabila ditinjau dari jenis kelamin maka tampak seperti tabel berikut ini:

Tabel 3. Perbedaan Gaya Belajar dan Jenis Kelamin Mahasiswa

\begin{tabular}{ccccc}
\hline \multirow{2}{*}{ Gaya Belajar } & \multicolumn{2}{c}{ Laki-laki } & \multicolumn{2}{c}{ Perempuan } \\
\cline { 2 - 5 } & Frekuensi & Persentase & Frekuensi & Persentase \\
\hline Visual & 5 & $10,2 \%$ & 2 & $8,3 \%$ \\
Aural & 12 & $24,5 \%$ & 7 & $29,2 \%$ \\
Read/write & 9 & $18,4 \%$ & 7 & $29,2 \%$ \\
Kinesthetic & 23 & $46,9 \%$ & 8 & $33,3 \%$ \\
\hline Total & 49 & $100 \%$ & 24 & $100 \%$ \\
\hline P value & \multicolumn{3}{c}{0,625} \\
\hline
\end{tabular}


Dari tabel 3 di atas tampak bahwa mahasiswa lakilaki yang memiliki gaya belajar visual sebanyak $5(10,2 \%)$, gaya belajar aural sebanyak $12(24,5 \%)$, gaya belajar read/write sebanyak $9(18,4 \%)$ dan gaya belajar kinesthetic sebanyak $23(46,9 \%)$. Untuk mahasiswa perempuan yang memiliki gaya belajar visual sebanyak $2(8,3 \%)$, gaya belajar aural sebanyak 7 (29,2\%), gaya belajar read/write sebanyak 7 $(29,2 \%)$ dan gaya belajar kinesthetic sebanyak $8(33,3 \%)$. Hasil uji statistik diperoleh nilai $\mathrm{p}=0,625$ maka dapat disimpulkan bahwa tidak ada perbedaan gaya belajar antara mahasiswa laki-laki dengan perempuan.

\section{Profil Motivasi Berprestasi Mahasiswa}

Motivasi berprestasi memiliki 3 dimensi, yaitu choice, persistence, dan effort. Nilai rata-rata dari ketiga dimensi di atas adalah sebagai berikut:

Gambar 1. Nilai Rata-Rata Dimensi Motivasi Berprestasi

\section{Dimensi Motivasi Berprestasi}

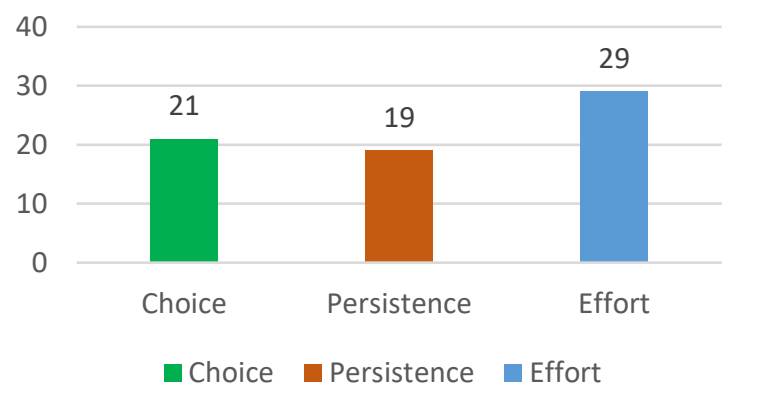

Dari gambar 1 di atas, tampak bahwa mahasiswa FIK Uncen memiliki dimensi effort lebih tinggi yaitu sebesar 29. Dimensi motivasi berprestasi mahasiswa yang paling rendah adalah persistence, yaitu sebesar 19, sedangkan dimensi choice memiliki nilai rata-rata sebesar 21. Hasil analisis perbedaan motivasi berprestasi mahasiswa FIK Uncen ditinjau dari jenis kelamin tampak seperti tabel di bawah ini:

Tabel 4. Perbedaan Motivasi Berprestasi dan Jenis Kelamin Mahasiswa

\begin{tabular}{lcccc}
\hline \multicolumn{1}{c}{ Jenis Kelamin } & N & Mean & SD & P-value \\
\hline Laki-laki & 49 & 65,37 & 20,891 & 0,135 \\
Perempuan & 24 & 74,88 & 26,765 & \\
\hline
\end{tabular}

Dari tabel 4 di atas tampak bahwa jumlah total mahasiswa laki-laki sebanyak 49 sedangkan jumlah mahasiswa perempuan sebanyak 24 orang. Nilai rata-rata (mean) motivasi berprestasi mahasiswa laki-laki sebesar 65,37 dengan standar deviasi (SD) 20,891, sedangka pada mahasiswa perempuan nilai rata-ratanya sebesar 74,88 dengan standar deviasi (SD) 26,765. Hasil uji statistik diperoleh nilai $\mathrm{p}=0,135$ maka dapat disimpulkan bahwa tidak ada perbedaan motivasi berprestasi antara mahasiswa lakilaki dengan perempuan.

\section{Profil Locus of Control Mahasiswa}

Berikut ini adalah deskripsi data locus of control mahasiswa FIK Uncen:

Tabel 5. Locus of Control Mahasiswa

\begin{tabular}{ccc}
\hline Locus of Control & Frekuensi & Persentase \\
\hline Internal & 63 & $86,3 \%$ \\
Eksternal & 10 & $13,7 \%$ \\
\hline Total & 73 & $100 \%$ \\
\hline
\end{tabular}

Dari tabel 5 di atas tampak bahwa mahasiswa yang memiliki locus of control internal sebanyak 63 (86,3\%), sedangkan yang memiliki locus of control eksternal sebanyak $10(13,7 \%)$. Apabila ditinjau dari jenis kelamin maka tampak seperti tabel berikut ini:

Tabel 6. Locus of Control dan Jenis Kelamin Mahasiswa

\begin{tabular}{ccccc}
\hline Locus of & \multicolumn{2}{c}{ Laki-laki } & \multicolumn{2}{c}{ Perempuan } \\
\cline { 2 - 5 } Control & Frekuensi & Persentase & Frekuensi & Persentase \\
\hline Internal & 41 & $83,7 \%$ & 22 & $91,7 \%$ \\
Eksternal & 8 & $16,3 \%$ & 2 & $8,3 \%$ \\
\hline Total & 49 & $100 \%$ & 24 & $100 \%$ \\
\hline P value & \multicolumn{3}{c}{0,481} \\
\hline
\end{tabular}

Dari tabel 6 di atas tampak bahwa mahasiswa lakilaki yang memiliki locus of control internal sebanyak 41 $(83,7 \%)$ orang, sedangkan yang memiliki locus of control eksternal sebanyak $8(16,3 \%)$ orang. Untuk mahasiswa perempuan yang memiliki locus of control internal sebanyak $22(91,7 \%)$ orang, sedangkan yang memiliki locus of control eksternal sebanyak $2(8,3 \%)$ orang. Hasil uji statistik diperoleh nilai $\mathrm{p}=0,481$ maka dapat disimpulkan bahwa tidak ada perbedaan locus of control antara mahasiswa laki-laki dengan perempuan.

\section{Profil Academic Self-Concept Mahasiswa}

Berikut ini adalah deskripsi data academic self-concept mahasiswa FIK Uncen:

\section{Tabel 7. Academic Self-Concept Mahasiswa}

\begin{tabular}{ccc}
\hline Academic Self-Concept & Frekuensi & Persentase \\
\hline Tinggi & 18 & $24,7 \%$ \\
Sedang & 55 & $75,3 \%$ \\
Rendah & 0 & $0 \%$ \\
\hline Total & 73 & $100 \%$ \\
\hline
\end{tabular}


Dari tabel 7 di atas tampak bahwa mahasiswa yang memiliki academic self-concept tinggi sebanyak 18 (24,7\%) orang, sedangkan yang memiliki academic self-concept sedang sebanyak $55(75,3 \%)$ orang, dan yang memiliki academic self-concept rendah $0(0 \%)$ orang. Apabila ditinjau dari jenis kelamin maka tampak seperti tabel berikut ini:

Tabel 8. Academic Self-Concept dan Jenis Kelamin Mahasiswa

\begin{tabular}{ccccc}
\hline Academic & \multicolumn{2}{c}{ Laki-laki } & \multicolumn{2}{c}{ Perempuan } \\
\cline { 2 - 5 } Self-Concept & Frekuensi & Persentase & Frekuensi & Persentase \\
\hline Tinggi & 11 & $22,4 \%$ & 7 & $29,2 \%$ \\
Sedang & 38 & $77,6 \%$ & 17 & $70,8 \%$ \\
Rendah & 0 & $0 \%$ & 0 & $0 \%$ \\
\hline Total & 49 & $100 \%$ & 24 & $100 \%$ \\
\hline P value & \multicolumn{3}{c}{0,532} \\
\hline
\end{tabular}

Dari tabel 8 di atas tampak bahwa mahasiswa lakilaki yang memiliki academic self-concept tinggi sebanyak 11 $(22,4 \%)$ orang, sedangkan yang memiliki academic selfconcept sedang sebanyak $38(77,6 \%)$ orang, dan yang memiliki academic self-concept rendah $0(0 \%)$ orang. Untuk mahasiswa perempuan yang memiliki academic self-concept tinggi sebanyak $7(29,2 \%)$ orang, sedangkan yang memiliki academic self-concept sedang sebanyak $17(70,8 \%)$ orang, dan yang memiliki academic self-concept rendah $0(0 \%)$ orang. Hasil uji statistik diperoleh nilai $\mathrm{p}=0,532$ maka dapat disimpulkan bahwa tidak ada perbedaan academic selfconcept antara mahasiswa laki-laki dengan perempuan.

\section{Simpulan dan Rekomendasi}

Berdasarkan hasil dan pembahasan di atas, maka dapat disimpulkan :

1) Terdapat $7(9,6 \%)$ mahasiswa yang memiliki gaya belajar visual, $19(26,0 \%)$ mahasiswa yang memiliki gaya belajar aural, 16 $(21,9 \%)$ mahasiswa yang memiliki gaya belajar read/write, dan 31 $(42,5 \%)$ mahasiswa yang memiliki gaya belajar kinesthetic. Tidak ada perbedaan gaya belajar mahasiswa FIK Uncen ditinjau dari jenis kelamin;

2) Nilai rata-rata motivasi berprestasi dimensi usaha mempunyai nilai lebih tinggi, yaitu sebesar 29 dibanding dengan dimensi pilihan (21) dan dimensi keuletan (19). Tidak ada perbedaan motivasi berprestasi mahasiswa FIK Uncen ditinjau dari jenis kelamin;

3) Terdapat $63(86,3 \%)$ mahasiswa yang memiliki locus of control internal, sedangkan yang memiliki locus of control eksternal sebanyak $10(13,7 \%)$. Tidak ada perbedaan locus of control mahasiswa FIK Uncen ditinjau dari jenis kelamin;

4) Terdapat $18(24,7 \%)$ mahasiswa yang memiliki academic selfconcept tinggi, sedangkan yang memiliki academic self-concept sedang sebanyak $55(75,3 \%)$ orang, dan yang memiliki academic self-concept rendah $0(0 \%)$ orang. Tidak ada perbedaan academic self-concept mahasiswa FIK Uncen ditinjau dari jenis kelamin.

Berdasarkan hasil penelitian tersebut, maka berikut rekomendasi yang disarankan yaitu :

1) Mahasiswa diberikan porsi lebih banyak untuk mempraktikkan dan mencoba tentang apa yang dipelajarinya dalam perkuliahan di FIK Uncen;

2) Pengajar perlu memberikan motivasi agar mahasiswa lebih ulet, tekun, atau gigih dalam belajar;

3) Pengajar perlu memberikan reinforcement secara konsisten pada mahasiswa ketika perkuliahan;

4) Penelitian yang akan datang hendaknya menambahkan analisis yang berkaitan dengan hasil belajar mahasiswa.

\section{Acknowledgements}

Ucapan terima kasih kepada Dekan Fakultas Ilmu Keolahragaan Universitas Cenderawasih yang telah mengijinkan melaksanakan penelitian. Ucapan terima kasih jugag kepada tim jurnal JOSSAE Fakultas Ilmu Keolahragaan Unesa yang telah mereviu dan memberikan masukan untuk sempurnanya artikel ini.

\section{Referensi}

Abimanyu, S. 1990. Hubungan antara Beberapa Faktor Social, Prestasi, Jenis Kelamin, dan Lokus Kendali dengan Kematangan Karir Siswa SMA. Disertasi, tidak diterbitkan. Malang: FPs UM.

Agustiani, H. 2006. Psikologi perkembangan. Bandung: Refika Aditama

Ary. D.. Jacobs. L.C.. \& Razavieh. A. 1990. Introduction to research in education 4th. New York: Harcourt Brace College Publisher.

Capel, S.A. 1992. Stress and Burnout in Teachers. European Journal of Teacher Education, 15 (3): 197-211.

Degeng, I.N.S. \& Pali, M. 2002. Model pembelajaran berorientasi pengembangan kecerdasan emosional di sekolah dasar: Faktorfaktor yang berpengaruh dalam rancangan pembelajaran. Laporan Riset, Ristek LIPI Jakarta.

Fleming, N.D., and Mills, C. 1992. Not another inventory, rather a catalyst for reflection. Tersedia di http://digitalcommons.unl.edu/podimproveacad/246 diunduh pada 19 April 2010.

Fleming, N., and Baume, D. 2006. Learning styles again: VARKing up the right tree! Educational developments, SEDA Ltd, Issue 7.4, Nov. 2006, 4-7.

Guay, F., Marsh, H.W., \& Boivin, M. 2003. Acedemic self-concept and academic achievement: Developmental perspectives on their causal ordering. Journal of educational psychology, 95 (1), 124136.

Hurlock, E. 1999. Psikologi perkembangan: Suatu pendekatan sepanjang rentang kehidupan. Jakarta: Erlangga. 
James, W. B., \& Blank, W. E. 1993. Review and critique of available learning style instrumens for adults. In D. Flannery (Ed.), Applying cognitive learning styles (pp. 47-58). San Francisco: Jossey-Bass.

Lent, R.W., Brown, S. D., \& Gore, P.A. 1997. Discriminant and predictive validity of academic self-concept, academic selfefficacy, and mathematics specific self-efficacy. Journal of Counselling Psychology, 44, 307-315.

Maksum, Ali. 2012. Metodologi Penelitian dalam Olahraga. Surabaya: Unesa University Press.

McClelland, D.C. 1961. The achieving society. New York: Van Nostrand.

McLoughlin, C. 1999. The implications of research literature on learning styles for the design of instructional material. Australian journal of educational technology, 15 (3), 222-241.

Murisal. 2003. Kesukarelaan siswa menjalani layanan bimbingan konseling. Jurnal konselor, 1(1): 41-51.

Nichols, J.D. 1984. Achievement motivation: conception of ability, subjective experience, task choice, and performance. Psychological review, Vol 91, 328-346.

Owie, M.W. 1993. Locus of control, instructional mode, and students achievement. Instructional Science, 12 (2): 383-388

Philibin, M. et al. 1995. A Survey of gender and learning style. Sex Role 32: 484-494.

Purwanto, Edy. 2011. Peningkatan motivasi berprestasi melalui penerapan model pembelajaran focused classroom meeting (MP-FCM): sebuah studi eksperimen pada siswa SMA. Disertasi, tidak dipublikasikan. Malang: FPs UM.

Putra, M.F.P. 2012. Pengaruh metode pembelajaran (STAD vs presentasi) dan lokus kendali terhadap hasil belajar (keefektifan dan daya tarik pembelajaran) mahasiswa pada matakuliah metodologi penelitian di jurusan pendidikan olahraga FIK Unesa. Tesis, tidak dipublikasikan. Malang: FPs UM.

Reigeluth, C.M. 1983. Instructional Design: What is It and Why is It? Dalam Reigeluth, C.M. (Ed.) Instructional-Design Theories and Models: A Overview of their Current Status. London \& New Jersey: LEA, publishers.

Reynolds, W.M. 1988. Measurement of academic self-concept in college students. Journal of Personality Assessment, 52 (2), 223-240.

Rotter, J.B. 1966. Generalized expectancies for internal versus external control reinforcement, Psychological Monograph. No. 80, 171208.

Schunk, D.H., Pintrich, P.R., \& Meece, J.L. 2008. Motivation in education: theory, research, and application $3^{\text {rd }}$. New Jersey: Pearson education, Inc.

Sugiyono. 2010. Statistika untuk Penelitian. Bandung: Alfabeta

Tjundjing, Sia. 2003. Keadalan VARK: Instrumen Modalitas Belajar Baru Yang Unik Da Menarik. Indonesian Psychological Journal, 18 (4), 241-361

Wigfield, A. \& Eccles, J.S. 2002. Development of achievement motivation. San Diego: academic press.
Zimbardo, P.G. 1980. Essentials of Psychplogy and Life $10^{\text {th }}$. United States of America: Scott, Foresman and Company. 